
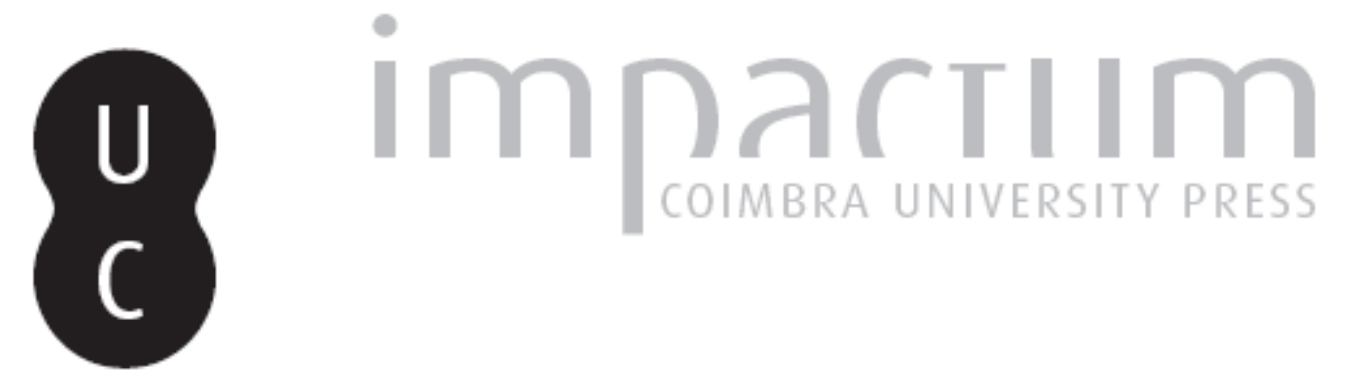

\title{
A arte rupestre na proto-história antiga do Vale de Besteiros: interpretação e territorialidade
}

Autor(es): $\quad$ Santos, André Tomás

Publicado por: Faculdade de Letras da Universidade de Coimbra

URL persistente:

URI:http://hdl.handle.net/10316.2/37721

DOI:

DOI:http://dx.doi.org/10.14195/1647-8657_45_4

Accessed : $\quad$ 26-Apr-2023 01:55:06

A navegação consulta e descarregamento dos títulos inseridos nas Bibliotecas Digitais UC Digitalis, UC Pombalina e UC Impactum, pressupõem a aceitação plena e sem reservas dos Termos e Condições de Uso destas Bibliotecas Digitais, disponíveis em https://digitalis.uc.pt/pt-pt/termos.

Conforme exposto nos referidos Termos e Condições de Uso, o descarregamento de títulos de acesso restrito requer uma licença válida de autorização devendo o utilizador aceder ao(s) documento(s) a partir de um endereço de IP da instituição detentora da supramencionada licença.

Ao utilizador é apenas permitido o descarregamento para uso pessoal, pelo que o emprego do(s) título(s) descarregado(s) para outro fim, designadamente comercial, carece de autorização do respetivo autor ou editor da obra.

Na medida em que todas as obras da UC Digitalis se encontram protegidas pelo Código do Direito de Autor e Direitos Conexos e demais legislação aplicável, toda a cópia, parcial ou total, deste documento, nos casos em que é legalmente admitida, deverá conter ou fazer-se acompanhar por este aviso.

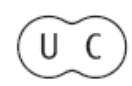




\section{CONIMBRIGA}

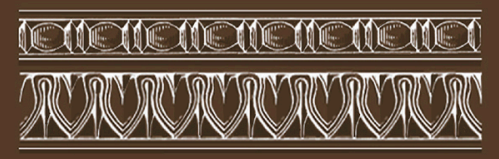

INSTITUTO DE ARQUEOLOGIA

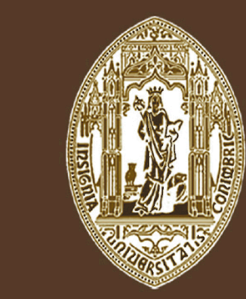

VOLUME XLV - 2006

FACULDADE DE LETRAS UNIVERSIDADE DE COIMBRA 
ANDRÉ TOMÁs SANTOS

Centro Nacional de Arte Rupestre.

E-mail: a.t.santos@sapo.pt

\section{A ARTE RUPESTRE NA PROTO-HISTÓRIA ANTIGA DO VALE DE BES- TEIROS: INTERPRETAÇÃO E TERRITORIALIDADE}

“Conimbriga" XLV (2006) p. 47-64

Resumo: A iconografia dos sítios de arte rupestre da Proto-história Antiga nesta região da Beira Alta caracteriza-se pela preponderância de motivos que se ligam a partes concretas do corpo humano. Este aspecto associado a outros que têm que ver com a própria localização e genealogia das estações, permitem-nos discutir a sua relevância no seio das comunidades coevas.

ABSTRACT: The rock art iconography of Late Bronze Age/Early Iron Age from this region of Beira Alta is strongly related with specific parts of the human body. This aspect associated with such as the location and genealogy of the sites enables us to discuss the relevance of them inside the coexistent communities. 
(Página deixada propositadamente em branco) 


\section{A ARTE RUPESTRE NA PROTO-HISTÓRIA ANTIGA DO VALE DE BESTEIROS: INTERPRETAÇÃO E TERRITORIALIDADE}

\section{Introdução}

A discussão que seguidamente se apresentará terá como objecto de análise uma série de sete estações de arte rupestre do concelho de Tondela cuja cronologia situamos no que genericamente consideramos como Proto-História Antiga, definindo-se este conceito por um momento de difícil precisão entre o Bronze Final e a I Idade do Ferro (Vilaça et alii, 2000, 190). Os trabalhos de campo que estiveram na base desta reflexão desenvolveram-se no âmbito do projecto "Práticas funerárias e/ou cultuais nos finais do Bronze na Beira Alta”, coordenado por Raquel Vilaça e Domingos Cruz, tendo-se desenvolvido com o apoio financeiro do IPA ao abrigo dos PNTA.

Não nos alargaremos sobre a base teórica subjacente a este trabalho, uma vez que já a expusemos noutros textos (Santos, 2003, 20-35; Santos, no prelo). Muito resumidamente, parte do princípio de que o Mundo deve ser entendido como um sistema de relações entre quem nele se situa (cada um de nós) e as pessoas, coisas e lugares que vai encontrando e com quem vai interagindo. Deste modo, a interpretação de um sítio arqueológico não se restringirá sobre o próprio, mas residirá sobretudo no tipo de relações que se poderão inferir entre aquele e os outros elementos que encontramos (ou criamos) em determinado contexto. De particular pertinência neste texto, será o próprio corpo de quem viveu (e vive) as estações que abordaremos, não só porque é através dele que percepcionamos o sistema de relações referido acima, como é ele próprio parte desse Mundo (Tilley, 2004, 2-4), e portanto passível de ser um dos elementos relacionais pertinentes para a interpretação dos sítios e, consequentemente das comunidades responsáveis pelo seu aparecimento. 


\section{A área de estudo}

O concelho de Tondela situa-se nos limites ocidentais da Beira Alta, integrando administrativamente o distrito de Viseu. Perceptivamente encontramo-nos perante duas unidades paisagísticas profundamente contrastantes (Est. I): praticamente toda a área do concelho corresponde à sub-região de Besteiros (Girão e Correia, 1939, 117), uma área de considerável platitude, com uma pujante rede hídrica e franca fertilidade; por outro lado, a ocidente deparamo-nos com a imponente vertente leste da serra do Caramulo, apta sobretudo para pastos e alguma agricultura de altitude (e nos últimos anos também para uma silvicultura de duvidosa relevância económica, onde se deve destacar o pinheiro e outras espécies mais próprias de regiões alpinas). A sub-região de Besteiros encontra-se geomorfologicamente na plataforma do Mondego, ampla superfície de aplanamento delimitada pelo Caramulo a oeste, pela Estrela a leste, pela Nave e o abrupto de Viseu a norte (Ferreira, 1978, 141). O Caramulo, por outro lado, corresponde à mais meridional serra das montanhas ocidentais (constituídas ainda pelo maciço da Galheira e pela serra de Montemuro). A imponência e majestade da vertente leste desta serra, deve-se, por um lado à sua origem neo-tectónica e, por outro, à diminuição de altitude de norte para sul dos planaltos que bordejam as montanhas ocidentais a oriente (Ferreira, 1978, 203). Durante toda a Pré-história Recente e Proto-história, este contraste terá certamente sido de extrema pertinência simbólica. Aliás, mesmo hoje, as montanhas ocidentais correspondem à fronteira geográfica entre a Beira Alta e a Beira Litoral.

Os monumentos megalíticos correspondem aos vestígios mais antigos da região. Encontram-se tanto nos níveis culminantes da serra como no vale. Podem encontrar-se sós ou agrupados em necrópoles de dois ou três monumentos. A maior concentração deste tipo de tumuli situa-se, no entanto, na área nordeste do vale e já na bacia do Dão (Santos, 2003, 4548). Entre estes últimos deve destacar-se, pelas magníficas pinturas no interior, o dólmen da Arquinha da Moura (Cunha, 1994; 1995). É, contudo, na referida zona nordeste que é mais evidente a relação entre este tipo de mamoas e as estações e arte rupestre que consideramos mais antigas. O exemplo paradigmático desta situação é o Fial, sítio que no seu interior dispõe também de uma enorme mamoa (Cabecinho da Mama) e de um conjunto de afloramentos gravados que pela sua disposição em planta, era até há bem pouco tempo interpretado como uma outra anta 
(a anta da Carvalha do Fial da bibliografia). Ainda com origem no Neolítico, podemos referir a estela-menir da Caparrosa (Est. I, 1) (Gomes e Monteiro, 1974-1977a; Gomes, 1993) que ocorre em estreita ligação, tanto com o monumento megalítico do Marco de Anta (Santos, 2003, 46), como com os três monumentos de Tecedeiras (Est. I, 2), estes de cronologia mais indefinida (Santos, 2003, 47). De cronologia também indefinida, mas integrável provavelmente ainda na Pré-história Recente, devemos citar os monumentos 3 e 4 do Sabugueiro (Est. I, 3), construídos em torno de outros dois mais antigos (Girão, 1921-22, 186, nota 1; Moita, 1966, 216; Santos, 2003, 46).

Outro tipo de mamoas com uma presença bastante considerável na área que agora nos importa correspondem às que, pelos paralelos com outros exemplos da região como Casinha Derribada (Cruz et alii, 1998) ou Senhora da Ouvida (Cruz e Vilaça, 1999), podemos considerar como integráveis no Bronze Final. Estes, até ao momento, só aparecem no vale, no topo de pequenas elevações e, se excluirmos o caso do possível monumento das Bouças (Est. I, 4) (Gomes et alii, 1994; Santos, 2003, 47), geralmente agrupados em necrópoles, sejam em torno de monumentos mais antigos como nos casos das necrópoles de Caramelo (Est. I, 5) (Girão, 1921-22, 186, nota 1; Moita, 1966, 215; Leisner, 1998, 68; Santos e Aveleira, 2001) e Mazugueira (Est. I, 6) (idem), sejam "construídas de raíz" como ocorre em Caramôlo (Est. I, 7) (Santos, 2003, 47) ou Pata do Cavalo (Est. I, 8) (idem). Para além destas pequenas mamoas, conhecemos também o caso do monumento sui generis do Paranho (Est. I, 9) (Coelho, 1925; Cruz, 1997). Não tendo sido construídos na serra, mesmo no vale existem numa área da região que não tinha sido pontuada previamente por outros tumuli - o sector sudocidental do vale, sendo nesta zona evidente a relação entre alguns destes sítios e parte das estações a que nos referiremos seguidamente. As estações de habitat que com alguma segurança podemos integrar neste período cronológico situam-se em duas zonas onde, até ver, não se identificaram quaisquer sítios funerários coevos. Assim, na bacia do Dão encontra-se o Castro dos Três Rios (Vaz, 1987, 23-25). Já no Caramulo, o sítio do Outeiro da Murada (Est. I, 10) poderá eventualmente ser também considerado contemporâneo (Cheney, 2000).

Seguidamente, apresentaremos então a análise em torno dos sítios que consideramos genericamente contemporâneos destes últimos, procurando descortinar as razões que estiveram na origem do seu aparecimento e qual a sua pertinência no contexto da Proto-história Antiga. 
Refira-se, no entanto, que Varela Gomes e Pinho Monteiro referem uma estação que pelas suas características poderia ser aqui integrada. Contudo, a estação de Picoto (Gomes e Monteiro, 1974-1977, 151) não foi localizada. A nossa localização na Est. I (11) foi feita a partir daquela publicação.

\section{Fial}

Esta estação foi já alvo de vários trabalhos (Girão, 1925, 88-90; Tavares e Silva, 1973, 262-263). Contudo, um estudo mais aprofundado que acabou por resultar numa tese de mestrado é relativamente recente (Santos, 2003). Situa-se num planalto levemente ondulado na área nordeste da área de estudo, sendo constituída por cinco núcleos intervisíveis entre si (Meal da Dona, Fial I, II, III e IV) que se distribuem por uma faixa orientada grosso modo no sentido oeste-este ao longo de menos de $1 \mathrm{Km}$ (Est. I, 12). O suporte geológico corresponde a anfibolitos cuja cor varia entre o esverdeado e os tons de castanho. Contudo, fruto do metamorfismo local, as superfícies apresentam uma camada ferruginosa de tonalidades compreendidas entre o vermelho e o laranja (Soen, 1958, 26). A maior parte do repertório figurativo da estação deve integrar-se num momento indeterminado entre o IV e III milénios A. C. Existem contudo alguns motivos cuja cronologia devemos situar, pelo menos, no Bronze Final, assim como outros já medievais e/ou modernos (Santos, 2003, 95). De momento interessa-nos os que se reportam a essa segunda fase.

Como está subentendido acima, a representatividade desta fase na estação é bastante reduzida quando comparada com o período precedente, para além do repertório que é, de igual modo, bastante circunscrito e monótono. Basicamente, encontramos quatro classes de motivos: cruciformes, ferraduras, podomorfos (Est. II) e antropomorfos.

Os cruciformes são motivos de difícil adscrição cronológica, podendo aparecer desde a Pré-história Recente até aos nossos dias. Muito importante para uma satisfatória resolução deste problema é a análise conjugada de diversos aspectos, sejam eles técnicos, estilísticos ou contextuais (no painel e na estação). Entre os que poderemos considerar como proto-históricos contam-se os presentes em Fial IV5 e IV6.

As segundas distinguem-se dos semicírculos (tão comuns na arte esquemática) pela maior longitude dos braços. A sua inserção no Bronze 
Final não é, no entanto, pacífica, correspondendo a motivos que são gravados até tempos muito recentes. No Fial, encontramo-las em duas das rochas que poderão ter sido gravadas de raiz no Bronze Final: Fial II 22 e IV5A.

Os podomorfos vamos encontrá-los não só aqui como também nas restantes estações que abordaremos, à excepção de uma. Serão também um importante elemento na altura da interpretação. Valerá a pena debruçar-nos um pouco sobre estes motivos. Aparecem um pouco por todo o país. No entanto, para efeitos de discussão cronológica abordaremos apenas algumas estações. No Escoural apareceu uma gravação deste tipo na rocha central (não selada pelos níveis calcolíticos) (Gomes et alii, 1983, 296-297). Podomorfos aparecem também nas estelas do sudoeste, em concreto na de Ervidel I (Gomes e Monteiro, 1976-1977, 292-297, fig. 3, est. V) e na de Gomes Aires (Almagro, 1966, 120, fig. 41), situáveis no Bronze Médio (Jorge, 1998, 114-115). Na necrópole do Pardieiro (Odemira), datada da I Idade do Ferro, duas tampas e uma das lajes que formava uma das sepulturas apresentam também podomorfos incisos, as duas primeiras associadas a epígrafes com escrita do sudoeste (Beirão, 1990, 111-114, figuras 4, 5 e 6). Recentemente, foi identificada uma laje gravada com um par de podomorfos imbricada no cairn de Monte Calvo I (Silva, 1997, 616-617), um pequeno monumento situado no Maciço da Gralheira, a que se pode atribuir uma cronologia já dentro de um Bronze avançado. Finalmente, será de referir também que na rocha 27 de Fial II é evidente a sobreposição de um círculo por um podomorfo. Admitimos, por outro lado, no seguimento de outros autores, a continuidade da gravação destes motivos até momentos muito recentes, como parece ser o caso da Portela da Pegadinha, sita também no concelho de Tondela (Santos et alii, no prelo). Este tipo de figuras encontra-se nas rochas de Meal da Dona 5A e 6A, Fial I 3 e 7, Fial II 25, 27 e 28A, Fial IV 1A e 6.

No Fial encontramos vários tipos de antropomorfos: aqueles que pelos seus paralelos com os existentes no interior dos megálitos e abrigos esquemáticos consideramos pré-históricos e os restantes que, para além de fugirem daquelas tipologias, são formados a partir de gravuras pré-existentes. Referimo-nos ao sulco vertical que antropomorfiza o rectângulo segmentado da rocha 6 de Fial I e à antropomorfização ainda mais evidente (porque para além daquele sulco, se observam também as pernas) dum motivo do mesmo tipo gravado no painel $\mathrm{B}$ da rocha 3 do mesmo núcleo. Dois sulcos convergentes no topo imediatamente à 
esquerda deste exemplo levam-nos a levantar a hipótese de nos encontrarmos perante uma outra figura humana reduzida aos seus membros inferiores.

Após estas considerações, recapitulemos os pontos-chave para a compreensão da estação no "tempo" que agora nos ocupa. O Fial no Bronze Final - Ferro Inicial tratava-se de um local onde rochas de cor anómala se encontravam profundamente marcadas por estranhas marcas executadas num Passado nebuloso (da autoria dos antepassados? Dos deuses?). Para além de tudo isto, entre estas rochas encontrava-se ainda mais uma daquelas "colinas" que demonstravam de igual modo, como noutras partes daquele sector do território, que o local tinha sido já "vivido" anteriormente. Por determinadas razões, as comunidades coevas (ou parte delas) entenderam materializar a sua relação com esse local através da gravação de novos motivos, também eles muito concretos. Essas razões que a esta situação levaram, quem gravou e porque gravou tão particulares motivos é o que discutiremos após um curto périplo pelas restantes estações da área de estudo...

\section{Valeira Ferradura}

Este sítio encontra-se no extremo sudocidental do concelho de Tondela, já muito perto do limite meridional da serra do Caramulo (Est. I, 13). Localiza-se na vertente oeste de um modesto contraforte daquela serra, em zona bastante cortada por pequenas linhas de água. De acordo com informadores locais, o caminho vicinal que passa poucos metros a leste seria a via de comunicação mais utilizada pelos pastores e o gado que se dirigiam para as feiras de Águeda, localidade situada já do outro lado do Caramulo.

Corresponde a um afloramento xistoso de morfologia bastante irregular. A superfície dispõe-se sub-horizontalmente. Nela encontramos três fases de gravação: uma que situamos num momento indeterminado situável entre os Finais do III e inícios do II milénio A. C., caracterizada por uma composição em torno de covinhas de diversos tamanhos e canais que ligam parte daquelas; uma segunda já proto-histórica representada por um podomorfo gravado marginalmente e uma ferradura; e uma terceira que consideramos já plenamente moderna que engloba os cruciformes (Santos et alii, no prelo). Os motivos do primeiro momento foram executados por picotagem seguido de abrasão, os do segundo 
apenas foram picotados; os do terceiro foram profundamente incisos com instrumento metálico. A cronologia da primeira fase tem como base argumentativa o paralelo com o grupo IX do Castro de Santa Tecla (Pontevedra, Galiza), sedimentado pelos níveis arqueológicos da estação (Costas, 1988, 42).

Mais uma vez encontramos uma "reutilização" de uma estação anterior e novamente nos deparamos com alguns dos motivos que no mesmo período foram gravados no Fial. Como lá, também aqui às comunidades proto-históricas lhes apareceu um sítio anteriormente frequentado e cujas interpretações que dele faziam certamente se distanciava verdadeiramente das nossas. De qualquer modo, possivelmente pelas mesmas razões e genericamente pelas mesmas pessoas foram aqui gravadas as mesmas figuras que no Fial.

\section{Molelinhos}

Trata-se de uma estação sobejamente conhecida da arqueologia portuguesa (Cortez, 1955, 92-96; Cunha, 1991). O sítio é constituído por seis painéis de xisto historiados, todos subverticais. A maior parte das gravuras foram incisas, identificando-se, no entanto, alguns exemplares picotados. Localiza-se no fundo de um vale junto à confluência de uma pequena linha de água com o rio Criz, no sector sudocidental da área em apreço neste texto (Est. I, 14). As fases de gravação seguras da rocha vão do Bronze Final à II Idade do Ferro, admitindo alguns autores que determinados "punhais, reticulados, escalariformes, e outros motivos geométrico-simbólicos" podem ser ainda integrados no Calcolítico (Gomes e Monteiro, 1976-1977, 332). Para além desses motivos geométricos atrás referidos e de alguns podomorfos, a estação destaca-se das restantes da região pela presença massiva de armas, correspondendo estas ao maior conjunto de figuras representadas.

Entre os aspectos que aqui queremos salientar contam-se os que se prendem com a localização da estação e o repertório figurado. Em relação ao primeiro ponto, consideramos altamente relevante o facto de se encontrar entre duas linhas de água. Por um lado, estes pontos são potencialmente frequentados por amplas audiências e, por outro, estamos num local que é(ra) ciclicamente submergido no Inverno. Ora isto tem implicações óbvias nas leituras que possamos fazer em torno da estação. Quanto ao segundo ponto e ainda relacionável com o primeiro, é parti- 
cularmente notável que seja neste sítio em particular que se gravem maioritariamente armas, situação aliás não singular nem no tempo nem no espaço. Na verdade, já Bradley havia notado que no Noroeste peninsular um número considerável de representações deste tipo se encontrava junto a rios e estuários (Bradley, 1997, 205). Se a esta constatação aliarmos a possível relação entre este género de gravuras e depósitos metálicos (Bradley, 1997, 203), torna-se bastante pertinente a situação topográfica de Molelinhos. Metaforicamente, encontramo-nos também perante um conjunto de armas que, de tempos em tempos, são depositadas nas águas. Ao contrário do que se passa nas deposições reais, estas armas são, no entanto, "recuperáveis". Ainda dentro do âmbito da iconografia aqui presente, voltamos a salientar o facto de também aqui terem sido gravados podomorfos, desta vez em clara associação com armas.

\section{Alagoa}

Trata-se de uma das estações mais singulares da nossa área de estudo. Localiza-se também no sector sudocidental do concelho de Tondela, em pleno leito de cheia de uma pequena linha de água que atravessa uma zona com uma topografia algo ondulada mas genericamente plana (Est. I, 15). A estação é constituída por oito painéis horizontais e sub-horizontais. Os motivos presentes resumem-se praticamente a podomorfos, mas existem também círculos, semicírculos e covinhas. Para além das gravuras propriamente ditas, observa-se ainda na estação uma estrutura negativa de planta sub-rectangular (Gomes e Monteiro, 1974-1977b). De relevar ainda a existência da necrópole do Caramolo a cerca de $1 \mathrm{Km}$ para este-sudeste.

Como se infere pelo que atrás se disse, também estas rochas são ciclicamente submergidas, de uma forma até mais rápida e prolongada que no caso anterior. Como discutiremos seguidamente, pensamos ser este um dado extremamente pertinente a ter em conta, em particular quando pensamos no repertório bastante sugestivo que aqui se verifica. De salientar também, o facto de alguns destes podomorfos, após análise morfo-técnica detalhada terem revelado a potencial necessidade da presença efectiva de um pé (Gomes e Monteiro, 1974-1977b, 162). Por outro lado, a proximidade relativa de uma necrópole provavelmente datada do Bronze Final é também particularmente pertinente se tivermos 
em conta a existência de podomorfos em monumentos deste tipo no macisso da Gralheira (vide supra).

\section{Carregueira}

Estação dada a conhecer por Varela Gomes e Pinho Monteiro (1974-1977b, 151). Corresponde a outro sítio do sector sudocidental do concelho (Est. I, 16). Trata-se de uma rocha com características muito semelhantes às de Alagoa. Como aquela, encontra-se em estreita associação com uma pequena linha de água, se bem que neste caso seria mais dificilmente submergida. Da mesma natureza é também o suporte - o xisto, dispondo-se os painéis horizontalmente e sub-horizontalmente. Encontra-se profundamente assoreada pelo que desconhecemos a dimensão real do sítio. Um dos painéis identificados foi, no entanto já estudado (Santos et alii, no prelo). Pelo que pudemos ver até ao momento, o repertório é, de igual modo, maioritariamente constituído por podomorfos (no caso do painel estudado, em número de sete, sendo que dois encontram-se gravados a par), tendo-se identificado também duas covinhas. Da mesma forma que em Alagoa, os motivos foram executados por picotagem, sofrendo as fossettes um posterior processo de polimento.

\section{Pata do Cavalo}

Trata-se da última estação do sector sudocidental (Est. I, 17). Localiza-se num modesto corgo já seco na meia encosta norte de um pequeno planalto. Este planalto tem, no entanto, uma particularidade, pois é aí que podemos observar a necrópole de Pata do Cavalo. A relação entre os dois sítios não é apenas de proximidade espacial. Na verdade, o caminho que ainda hoje leva à necrópole é precisamente através desse corgo onde se localiza a rocha, encontrando-se os primeiros monumentos que compõem aquela imediatamente à esquerda do começo do corgo já no topo do planalto.

Quanto à rocha em si, esta corresponde a um painel subvertical de natureza xistosa. Nele identificam-se apenas uma ferradura profundamente picotada e nove covinhas executadas com a mesma técnica (Santos et alii, no prelo). 


\section{Laja das Côcas}

Corresponde esta estação ao nosso único exemplo situado na serra do Caramulo, a meia-encosta da sua vertente leste, já na metade setentrional da nossa área de estudo (Est. I, 18). A estação é conhecida da bibliografia portuguesa desde os anos quarenta (Silva, 1947; Tavares e Silva, 1973, 262). No entanto, só durante os trabalhos de campo do CEPBA foram efectuados os decalques correspondentes (Santos et alii, no prelo). De referir ainda que o sítio se encontra, em parte, no alinhamento de um caminho antigo, facto que explica o forte desgaste (fruto dos rodados de antigos carros de tracção animal) do sector sul do painel principal. Este caminho corresponde a mais uma antiga via que atravessa a serra. Esta antiguidade não é só inferida pelo desgaste do sector atrás referido como também a partir da própria toponímia do lugar de onde, a partir do vale, arranca o caminho - Portela do Guardão.

A estação corresponde a um grande afloramento granítico subhorizontal onde se encontram gravadas por abrasão várias covinhas de diversos tamanhos associadas aos pares e a sulcos rectos, formando o que parecem ser falos de diversos tamanhos (Est. III). Em alguns destes está figurada também a glande fálica. Em menor quantidade, aparecem semicírculos e alguns podomorfos. Em torno deste afloramento, identificaram-se ainda oito blocos onde figurações fálicas e covinhas se encontram representados. Os primeiros em painéis verticais, as segundas em horizontais.

Os falos dos painéis principais (porque maiores e centrais) orientam-se para leste, isto é, para o vale e para quem observa a estação. Os que se encontram nos blocos à volta orientam-se para a rocha central.

Precisar a cronologia desta rocha é bastante difícil. Contudo os podomorfos dão-nos já uma indicação. Indicação essa que não contraria as conclusões a que podemos chegar a partir dos poucos paralelos a que é possível recorrer. Assim, na Meseta conhecemos a estação de La Peña de Santa Maria onde um falo se encontra associado a podomorfos (Benito e Grande, 2000, 125-126). Mesmo em Portugal, em Trás-os-Montes um possível motivo deste tipo poderá estar representado no abrigo da Solhapa (Mourinho, 1972; Sanches e Lebre, 1986), estação datada do Bronze Final pelas últimas autoras citadas. 


\section{Dos Corpos, dos Lugares e do Tempo: Elementos para uma Genealogia do Poder}

Como já defendemos anteriormente, o Bronze Final corresponde a um período em que o Poder se manifesta sob diversas formas e em diversos contextos (Santos, 2003, 144-145). Não só nos sítios de habitat (Vilaça, 1995; 1998), não só nas necrópoles cujas escavações apontam para rituais que não teriam apenas que ver com a manipulação dos cadáveres (Vilaça e Cruz, 1999), mas também na arte rupestre coeva. Pretendemos neste último ponto, e recorrendo aos sítios atrás referidos, procurar descortinar como se daria esse processo no caso concreto da arte rupestre.

Em última instância, o fenómeno da arte rupestre poderá ser encarado como signos apostos sobre um suporte rochoso. Signos esses cujas referências (ou significados) absolutas nos escapam. Contudo, aquelas encontravam-se também num Mundo. Quanto mais conseguirmos nele entrar, mais possibilidades temos de aquelas referências encontrar ou pelo menos divisar as que não entrem em contradição com aquele. Ora, os signos figurativos que temos em mãos (isto é, se excluirmos as covinhas e motivos geométricos de Molelinhos) organizam-se em dois grupos: os que se relacionam com o próprio corpo (antropomorfos, podomorfos e falos) e os que representam realidades exteriores àquele (armas e ferraduras). Destes, o primeiro grupo está representado em todas as estações à excepção de Pata do Cavalo. A primeira constatação é que, e recorrendo a um raciocínio metonímico, o único sítio onde o "corpo" não está gravado é naquele onde é fisicamente manipulado (porque claramente associado a uma necrópole). Podemos pois com toda a propriedade afirmar que o corpo enquanto representação está presente em todas as estações. Mas que corpo é esse?

É neste ponto que podemos aprofundar a questão dos podomorfos. Como se escreveu acima, a partir da análise morfo-técnica efectuada sobre os podomorfos da Alagoa, Varela Gomes e Pinho Monteiro chegaram à conclusão de que alguns deles precisavam de um corpo efectivo. Mesmo na Galiza, este facto parece também passar-se, razão pela qual alguns autores relacionaram estes motivos com investiduras reais de raiz céltica (Santos e García, 2000; García e Santos, 2000). Daqui inferimos que cada podomorfo poderá referir-se apenas a um indivíduo (ou a uma fracção reduzida da comunidade) em particular, mesmo se em determinada altura já são feitos sem recurso a um modelo real. Daqui se 
subentende que, à excepção de Alagoa, os sítios que temos são apropriados por elementos muito específicos da comunidade. É essa a nossa primeira evidência de manifestação de Poder. Antes de voltarmos a Alagoa e aos restantes signos, vejamos algumas particularidades que todos os sítios têm enquanto lugares.

$\mathrm{Na}$ verdade, se há algo que têm em comum todos estes sítios é o facto de em todos eles, seja pelas suas características intrínsecas, seja pela iconografia lá expressa, corresponderem a manifestações concretas (físicas) do Tempo. Se isto é evidente em sítios como o Fial ou a Valeira Ferradura porque têm gravuras mais antigas, nos outros haverá necessidade de aprofundar o porquê. Assim, em Alagoa, Molelinhos e Carregueira é o facto da emersão e imersão das rochas que concretiza uma ideia de ciclicidade (uma forma bastante especial de temporalidade). Em Pata do Cavalo, é a sua associação clara à ideia de morte que nos permite inferir isto. Na verdade, o último suspiro de um corpo corresponde ao sinal mais evidente de que nos integramos temporalmente, que temos um fim, assim como um princípio, este último reflectido na Laja das Côcas e na iconografia nela representada. Porque relevamos nós este aspecto? Em primeiro lugar porque característica importante do Poder enquanto tal é a sua necessidade de manutenção. O que aqui vimos é precisamente o exaltar da ciclicidade, ou se quisermos eternidade, do Poder. Vimos também que, salvo duas excepções (Alagoa e Carregueira), associados a esse Poder estão só alguns (representados pelos poucos podomordos representados). Por outro lado, poderão essas excepções corresponder aos sítios onde a totalidade da comunidade se representaria. A resposta a esta questão dependeria da diacronia de gravação dessas rochas. Não nos repugna a ideia de mesmo aí só alguns aporem os seus pés. Contudo, dificilmente podemos confirmar ou infirmar tal sugestão.

Finalmente, podemos, com base na iconografia própria de cada estação e nas relações que estas estabelecem com a envolvente, proceder a análises mais específicas de cada uma delas e inferir a sua importância simbólica no contexto a que nos reportamos. Assim, no Fial e na Valeira Ferradura parece-nos claro que é a prévia existência de gravuras que as imbui de particular relevância. A apropriação e controlo interpretativo do passado pode constituir em si uma óptima forma de ostentar e legitimar o Poder. Este fenómeno (que se verifica até hoje) observa-se não só na arte rupestre como também nas necrópoles coevas que se criam em torno de antigos monumentos (vide supra). Se a antropomorfização de alguns dos 
motivos do Fial pode ser encarada como uma evidência de recalibragem interpretativa, os poucos podomorfos representados permitem-nos inferir que a apropriação era apenas feita por alguns.

Da mesma forma, também só alguns se associam às armas de Molelinhos. Se discutimos já a relevância do Tempo nesta estação e da sua consequente relação com o Poder, por demais evidente é também a relação deste com as armas aqui documentadas.

No caso da Laja das Côcas a exaltação do Poder é em si também a exaltação de um género. Já escrevemos que "podemos interpretar o sítio como um elemento legitimador de uma dada ordem social em que o varão tem especial importância, aparecendo dotado de um papel gerador, neste caso, de relações sociais", sendo reforçada esta ideia pela própria localização da estação a meia encosta de uma serra que seria (e é ainda hoje pelos habitantes locais) vista como responsável pela fecundidade, perdão, fertilidade do vale (Santos, 2003, 145). $\mathrm{O}$ facto destas rochas se encontrarem junto a um caminho antigo de particular importância leva-nos a admitir que o sítio seria "vivenciado" recorrentemente, facilitando assim a assimilação desta ideia de forma natural.

O sítio de Pata do Cavalo é mais difícil de explicar. Na verdade, trata-se do único que não apresenta qualquer podomorfo. No entanto, esses corpos cujos podomorfos "substituiriam" encontram-se aí ao lado. Corresponde, de facto, esta estação à que ao nível da proximidade mais perto se encontra do referente físico que temos vindo a valorizar ao longo do texto.

Já Alagoa e Carregueira (e eventualmente Picoto), independentemente da representatividade social existente nestas estações, parecem-nos relacionar-se com ritos de integração social. Por um lado, se explicaria a presença quase exclusiva de podomorfos. Por outro, que estas cerimónias se passassem num sítio onde a ciclicidade também se manifesta de forma muito premente é particularmente significativo quando uma das funções destes ritos é precisamente afirmar a continuidade da comunidade no Tempo. A estrutura negativa identificada em Alagoa poderá ter que ver com esses ritos.

Teritorialidade foi definida por Tim Ingold como "um modo de comunicação, servindo para passar informação sobre indivíduos dispersos pelo espaço" (1986, 133). Com este texto, tentámos demonstrar que essa informação passava muito pelas manifestações de exaltação e legitimação de Poder de dada parte da sociedade. Essas manifestações 
não passavam apenas pela iconografia representada em cada estação mas pelo jogo desempenhado entre aquela e a os lugares vivenciados. O Poder não seria algo de abstracto mas corporizado, conotativa e denotivamente. São esses corpos específicos através dos quais o Poder se manifesta que encontramos metonimicamente representados nas nossas estações. Através da sua aposição nestes sítios especiais inscrevem-se também numa pretensa eternidade, expressa pela ciclicidade temporal que aqui se percepciona fisicamente. Contudo, e tal como agora, a História não acabou aí e o Poder seguramente mudou (e mudará) de mãos...

\section{BIBLIOGRAFIA}

Almagro Gorbea, M. J., Las Estelas decoradas del Suroeste peninsular, [Biblioteca Praehistorica Hispana, 8], Madrid, 1966.

BEIRÃo, C. de M., "Epigrafia da I Idade do Ferro do Sudoeste da Península Ibérica. Novos dados arqueológicos”, Estudos Orientalizantes em Portugal. Da Pré-História ao Período Romano, Lisboa, 1990 107-118.

BENITO DEL REY, L. e GRANDE DEL BRÍo, R., Santuários rupestres pré-históricos en el Centro Oeste de España, Salamanca, 2000.

Bradley, R., Rock Art and the Prehistory of Atlantic Europe, Londres e Nova Iorque, 1997.

Cheney, A., Outeiro Murado [Seminário de Licenciatura do curso de História, variante de Arqueologia entregue à Faculdade de Letras da Universidade de Coimbra] Coimbra, 2000.

Coelho, J., A necrópole de Paranho, [Estudos Preistóricos, vol. II], Viseu, 1925.

Cortez, F. R., "Contribuicion al estúdio de la Protohistoria de los "Lusitani" (entre el Duero y el Tajo), Archivo Español de Arqueologia, 281955 90-101.

Costas Goberna, F. J., "Consideraciones sobre la posibilidad de acercamento cronologico a los petroglifos del Castro de Santa Tecla", Revista de Ciencias Históricas, 31988 39-55.

CRuz, D. J. da, “A necrópole do Bronze Final do "Paranho" (Molelos, Tondela, Viseu)", Estudos Pré-históricos, 51997 85-109.

Cruz, D. J., Gomes, L. F. e Carvalho, P. M. S. "O grupo de tumuli da "Casinha Derribada" (concelho de Viseu), Conimbriga, 37 1998 5-76.

Cruz, D. J. e VIlaçA, R., "O grupo de tumuli da "Senhora da Ouvida" (Monteiras / Moura Morta, Castro Daire, Viseu) Resultados dos trabalhos arqueológicos", Estudos Pré-históricos, 71999 129-161.

Cunha, A. M. C. L. da, "Estação de arte rupestre de Molelinhos. Notícia preliminar", Actas das IV Jornadas Arqueológicas (Lisboa 1990), Lisboa, 1991 253-258. 
Cunha, A. M. C. L. da, "Un dólmen peint portugais, Anta da Arquinha da Moura", Dossiers d'Archéologie, 3041994 50-53.

Cunha, A. M. C. L. da, "Anta da Arquinha da Moura (Tondela)", Trabalhos de Antropologia e Etnologia, 35(3) 1995 133-140.

Ferreira, A. B., Planaltos e montanhas do Norte da Beira - Estudos de Geomorfologia [Memórias do Centro de Estudos Geográficos, n. ${ }^{\circ}$ 4], Lisboa, 1978.

García Quintela, M. V. e Santos Estévez, M., "Petroglifos podomorfos de Galicia e investiduras reales célticas: Estudio comparativo", Archivo Español de Arqueologia, 732000 5-26.

GIRÃO, A. A., "Monumentos pré-históricos do concelho de Viseu", O Archeologo Português, série I 25 1921-1922 183-189.

Girão, A. de A., “Arte rupestre em Portugal (Beira Alta)”, Biblos, 11925 81-95.

Girão, A. de A., CorreiA, V., Excursões no Centro de Portugal, Coimbra, 1939.

Gomes, M. V., "O Marco de Anta ou estela-menir de Caparrosa (Tondela - Viseu)", Estudos Pré-históricos, 11993 7-27.

Gomes, R. V., Gomes, M. V. e Santos, M. F., "O santuário exterior do Escoural. Sector NE (Montemor-o-Novo, Évora), Zephyrus, 361983 287-307.

Gomes, M. V. e Monteiro, J. P., “A estela-menir decorada da Caparrosa. Beira-Alta. Nota da descoberta”, O Arqueólogo Português, série III 8-9 1974-1977a 89-93.

Gomes, M. V. e Monteiro, J. P., “As rochas decoradas de Alagoa. Tondela - Viseu”, O Arqueólogo Português, série III 8-9 1974-1977b 145-164.

Gomes, M. V. e Monteiro, J. P., “As estelas decoradas da herdade do Pomar (Ervidel - Beja) - Estudo comparado”, Setúbal Arqueológica, 2-3 1976-1977 281-343 .

INGOLD, T., The appropriation of nature: Essays on Human Ecology and social relations, Manchester, 1986.

Jorge, S. O., "Bronze age stelai and menhirs of the Iberian Península: Discourses of power", Gods and heroes of the Bronze age, Europe at the time of Ulysses, Londres, 1998 114-122.

LeISNER, V., Die Megalithgräber der Iberischen Halbinsel, Der Westen, Berlim, 1998. MoitA, I., "Características predominantes do grupo dolménico da Beira Alta", Ethnos, 5 1966 189-277.

Mourinho, A. M., "O Abrigo rupestre da "Solhapa" - Em Duas Igrejas, Miranda do Douro", O Arqueólogo Português, série III 51972 33-55.

SANCHES, M. J. e Lebre, A. G., "O abrigo gravado com arte esquemática da Solhapa (Duas Igrejas - Miranda do Douro)", Trabalhos de Antropologia e Etnologia, 26 (1-4) 1986 129-142.

Santos Estévez, M. e García Quintela, M. V., "Petroglifos podomorfos del Noroeste Peninsular: Nuevas comparaciones e interpretaciones", Revista de Ciências Históricas 152000 7-40.

Santos, A. T., Uma Abordagem Hermenêutica - Fenomenológica à Arte Rupestre da Beira Alta. O caso do Fial (Tondela, Viseu) [Dissertação de mestrado apresentada à Faculdade de Letras da Universidade do Porto], Porto, 2003. 
SAntos, A. T. "A Fenomenologia da Pré-história e a Arte Rupestre ou 'Como o martelo só se revela no acto de martelar' ", Actas do IV Congresso de Arqueologia Peninsular, no prelo.

Santos, A. T. e Aveleira, A., "A necrópole de "Caramelo - Mazugueira” (Caparrosa, Tondela, Viseu)", Estudos Pré-históricos, 92001 123-131.

Santos, A. T., Cheney, A., Aveleira, A., "A arte rupestre no concelho de Tondela: Uma perspectiva diacrónica", Actas do II Congresso de Arqueologia de Trás-os-Montes, Alto Douro e Beira Interior, no prelo.

Silva, C. T. da, "Vestígios pré-históricos de Besteiros. I - A Laja das Cocas", Beira Alta, 61947 291-230.

Silva, F. A. P., "Contextos funerários da Idade do Bronze nos Planaltos Centrais do Centro - Norte Litoral Português: tradição ou inovação?", II Congresso de Arqueologia Peninsular, 21997 605-620.

SoEn, Y. O., The geology petrology and ore deposits of the Vizeu region, northern Portugal, Lisboa, 1958.

Tavares, A. A. e Silva, C. T., "Gravuras e inscrições rupestres da região de Viseu", Actas do II Congresso Nacional de Arqueologia, Coimbra, 1973 261-270.

TILley, C., The Materiality of Stone, Oxford e Nova Iorque, 2004.

VAZ, J. L. I., Roteiro arqueológico do concelho de Viseu, Viseu, 1987.

VILAÇA, R., Aspectos do povoamento da Beira Interior (Centro e Sul) nos finais da Idade do Bronze [Trabalhos de Arqueologia, 9], Lisboa, 1995.

VILAÇA, R., "Hierarquização e conflito no Bronze Final da Beira Interior" in JoRgE, S. O., Existe uma Idade do Bronze Atlântico? [Trabalhos de Arqueologia, 10], Lisboa, 1998 203-217.

VilaçA, R., Cruz, D. J., "Práticas funerárias e cultuais dos Finais do Bronze na Beira Alta”, Arqueologia, 241999 73-99.

Vilaça, R., Santos, A. T., Porfírio, E., Marques, J. N., Correia, M. Canas, N., "O povoamento do I milénio A. C. na área do concelho do Fundão: Pistas de aproximação ao seu conhecimento", Estudos Pré-históricos, 82000 187-219. 


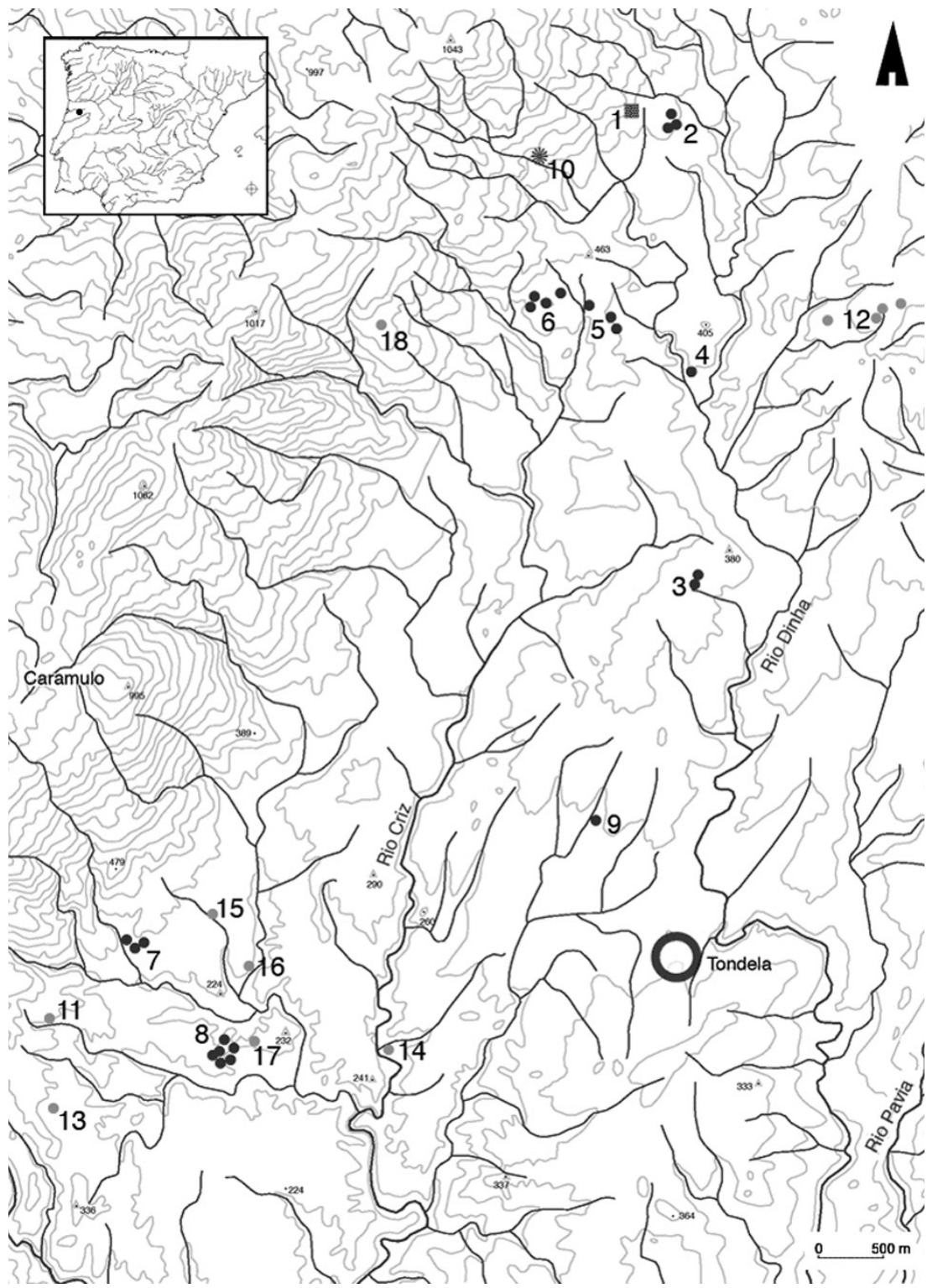

Localização das estações proto-históricas referidas no texto (Base cartográfica:

Carta 1: 100 000, folhas 16 e 17). Os círculos escuros representam os tumuli, os cinzentos as estações de arte rupestre. O quadrado marca a estela-menir e o a estrela um povoado. A identificação das estações é referida ao longo do trabalho. 
EST. II
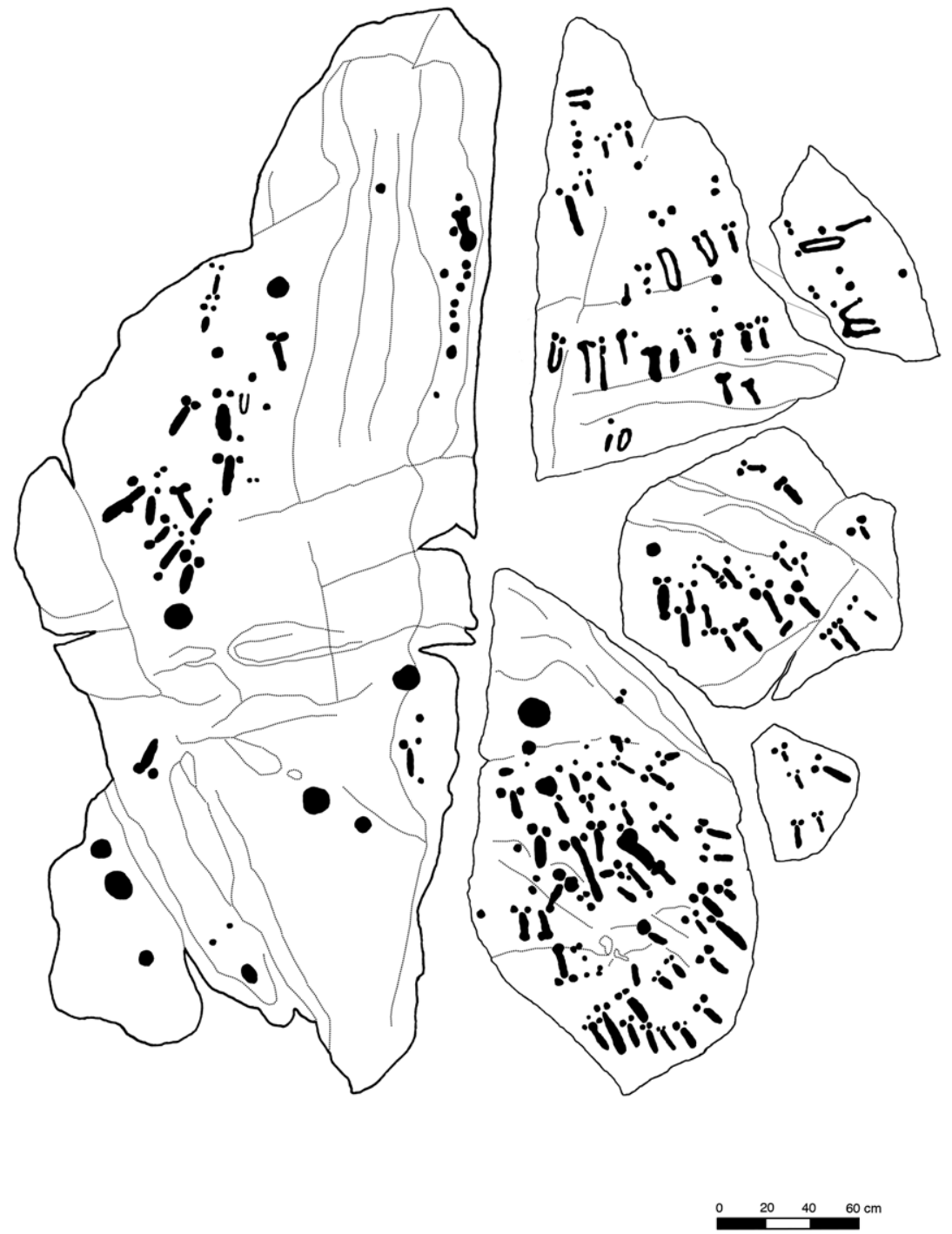

Rocha 25 de Fial 2. Os podomorfos encontram-se destacados, assim como as cruzes que se lhes sobrepõem. 


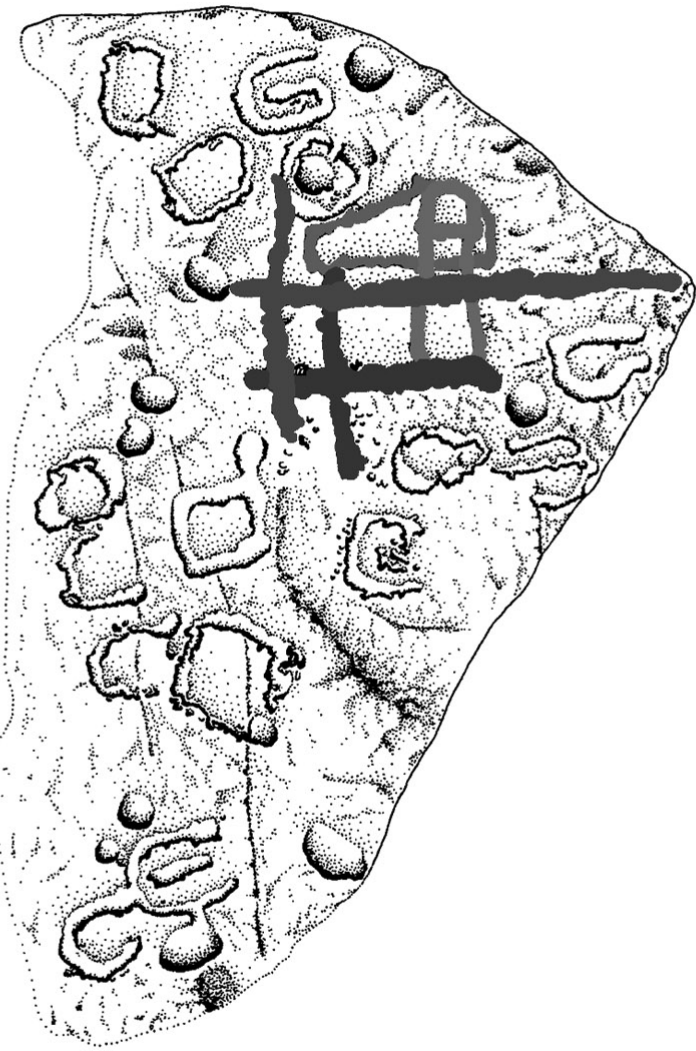

